\title{
How to Manufacture an Automatic Car
}

\author{
Koram Samuel Sakyi* and Jian Fei Lu \\ School of Civil Engineering and Mechanics, Jiangsu University, China
}

Submission: May 19, 2019; Published: June 13, 2019

*Corresponding author: Koram Samuel Sakyi, School of Civil Engineering and Mechanics, Jiangsu University, China

Abstract

This research seeks to implement a novel technique of a mobile vehicle which works automatically. In this paper, we shall know how to manufacture an automatic car that works with GPS location and other radioactive elements. Formerly, cars were produced by means of an amalgamation of mechanism and humanoid control. Car fragments, for example engines and rims, were manufactured in huge quantities by machineries. However, each car was pressed down a conveyor belt and amassed bit by bit, till it was set to be dispatched off to its owner. The methods of manufacturing a car can be roughly alienated into engraving, welding, assembling, painting and inspection, which takes approximately 17-18 hours to complete. This differs rendering to the number of cars manufactured by each factory.

Keywords: Manufacture; Automatic Car; Element; Engraving; Assembling; Painting; Inspection

\section{Introduction}

Over the last many years, the world's prominent producer of cars is China, as the nation's 2015 manufacture gave rise to the accomplishment of 24,503,326 motor-powered or motorized cars. What actually goes into the manufacturing of automatic cars? Cars are manufactured by an extensive variety of resources, for example steel, aluminum, copper, glass, rubber, and distinct fibers. First of all, a raw material manufacturing industry takes different raw materials and chances them into supplies that can be used to manufacture car parts and dispatch them to parts manufacturing companies or to Toyota. Nevertheless, we on no occasion actually give ample thought to the bits and fragments of raw supplies that are used in auto manufacturing to produce these cars. There are numerous of raw materials that are used in auto manufacturing. The car production uses a great number of supplies to manufacture cars, comprising iron, plastic steel, glass, copper, rubber, petroleum products, aluminum, and steel among others. Let's take a typical example of how Lamborghini are manufactured. Every single Lamborghini ever manufactured was assembled by hand in industries. Nowadays, robots are being used at various car factories across the globe, however in Sant'Agata Bolognese, Italy, Lamborghini is taking the reverse course. Meanwhile, the paraphernalia that goes into the manufacturing of automatic cars are perhaps half the price of manufacturing and of course is essential to be substituted every 20 to 30 years. If you manufacture one million automatic cars each year, then you would manufacture 30 million cars in 30 years. Therefore, the cost of manufacturing a car approximately ranges from $\$ 100$ to $\$ 500$ per car to wage for its infrastructure.

\section{Methodology}

\section{Engraving}

This is an initial stage of design, where an architectural view of the automatic car is made. The sketch below is a typical example of an automatic car. (Designed with AutoCAD by Samuel Sakyi Koram) [1-25] (Figure 1).

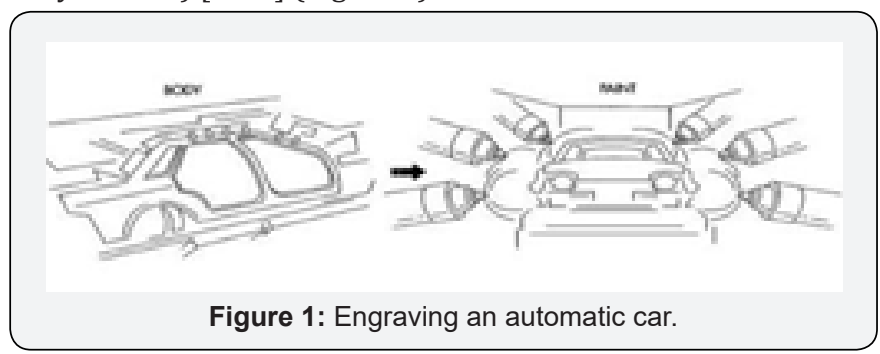

\section{Welding}

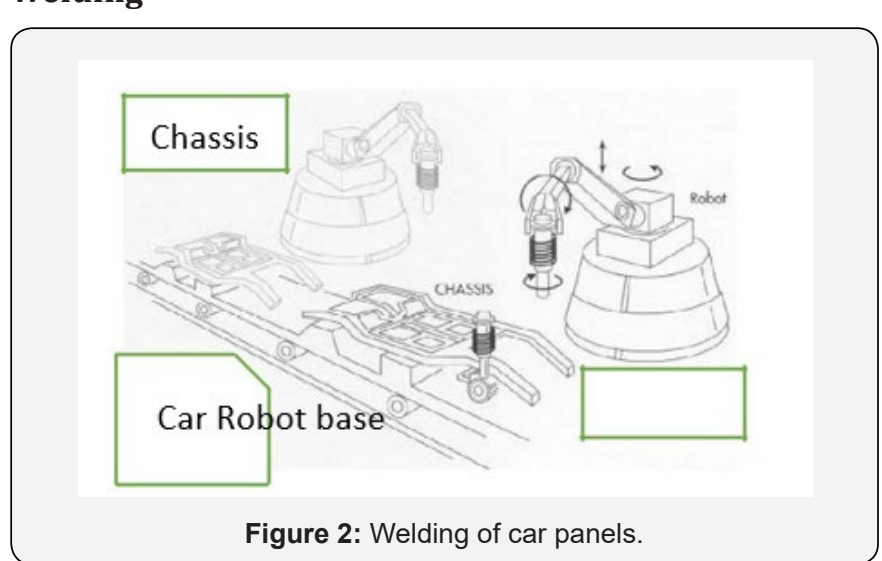


For the duration of welding, component parts are held firmly in a jig whereas welding processes are made. As soon as the body case is complete, it is then fixed to an overhead conveyor for the painting to commence. The multi-step painting course involves checkup, washing, first coat (applied electrostatically) dipping, drying, topcoat spewing, and sweltering smoke, weld sparkles, and gases produced throughout this stage of manufacturing (Figure 2, 3).

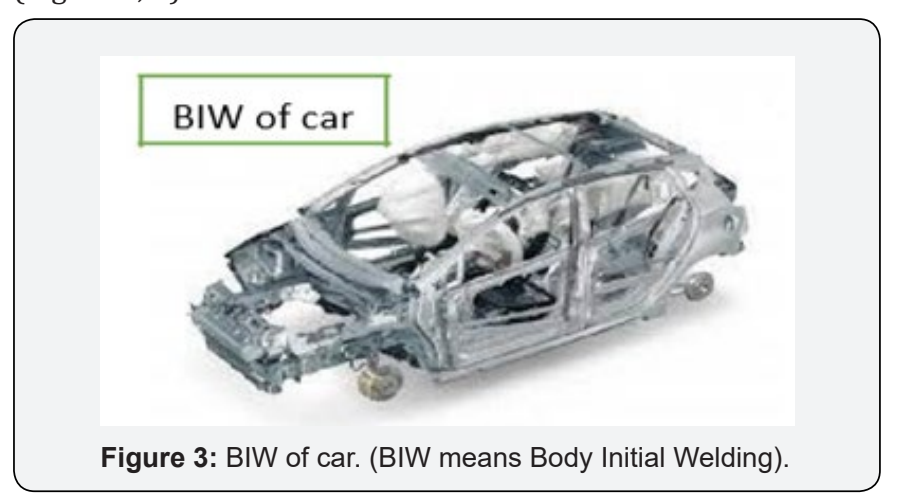

Steps of Car Manufacturing

To some extent all automobile elements would be alienated into six (6) workshops namely:

\section{Engine workshop}

This is where the engine block manufacturing is made rendering to measurements and supplementary engine fragments are also amassed.

\section{Transaxle workshop:}

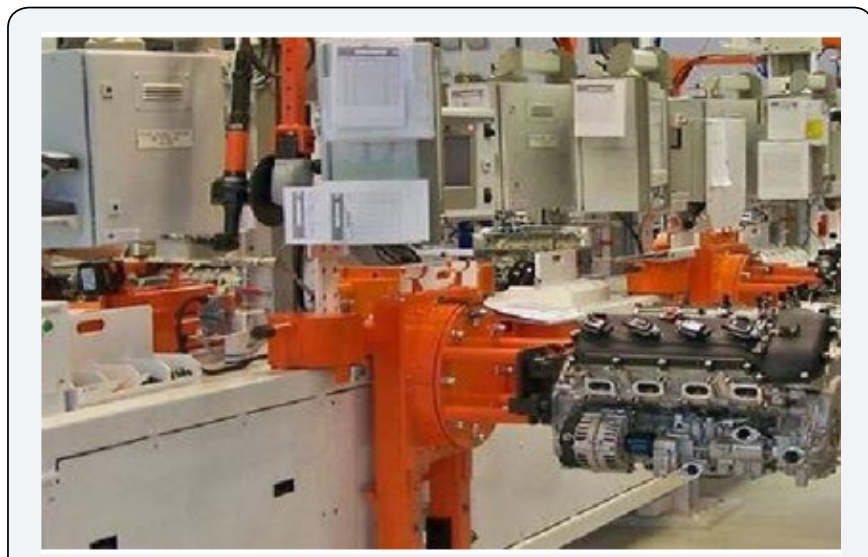

Figure 4: Engine amass line.

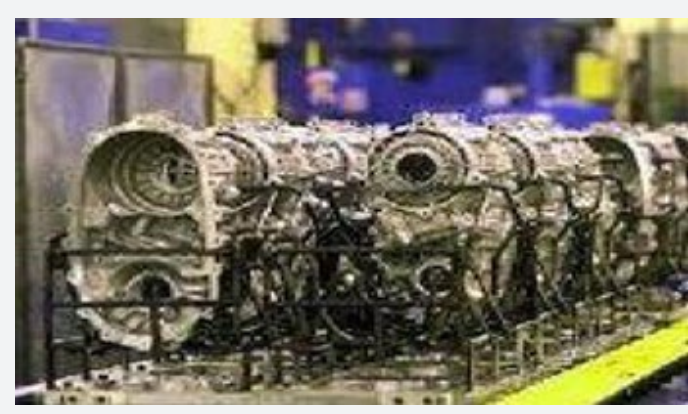

Figure 5: Gear-box line.
Complete machining of gear breaks, shafts and amass of gear box is completed at this workshop. The gear box is moved to the engine workshop where it is tailored with engine and then an element is generated called the powertrain (Figure 4,5).

\section{Press workshop}

The sheet metal processing takes place at this workshop where the diverse panels of the automatic car are manufactured such as doors, pillars, hood, and roof among others (Figure 6,7).

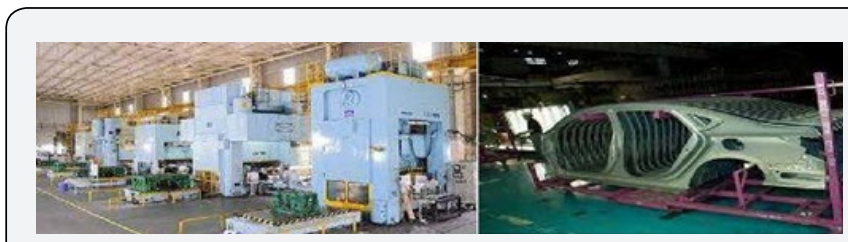

Figure 6\&7: Hydraulic forging machineries in press workshop \& Car panels from press workshop.

\section{Weld workshop}

Welding of these panels is completed, and the body manufactured is termed as body in white (BIW signifies Body Initial Welding).

\section{Paint workshop}

As the name implies, the painting of the entire whole body is completed, and painted body is sent for final assembling. TCF workshop- Trim Chassis: This is the final workshop where they assemble the engine with the body accompanied by additional parts such as wheels, seats dashboard, wind shield, air conditioner among others.

\section{Evaluation and conclusion}

\section{Testing}

Finally, various tests are undertaken such as shower test, DLT test, drive test among others and lastly an automatic car rolls out of the unit. These processes above show the assembling, painting and inspection phases of manufacturing an automatic car.

\section{References}

1. Sakyi KS, Jian-Fei L (2019) The Efficient and Tentative Model for Extenics Replications of the Moveable Robots. The Open Mechanical Engineering Journal 13: 1.

2. Sakyi KS (2018) Conveyance Heat Transfer in Solid Structures/Koram Samuel Sakyi/PhD in Solid Mechanics.

3. Sakyi KS (2019) Duties of the building team members.

4. Sakyi KS (2019) The Building Team.

5. Sakyi KS (2019) The Work of Building Construction Development Team Members In Building Projects Distribution.

6. Sakyi KS, Jian-Fei Lu (2019) Dynamic analysis of periodic saturated soil-structure system with Finite Element Method. The Open Civil Engineering Journal 13(13): 9-21.

7. Jun Yu, Haiming C, Zhao Y, Cheng L (2009) Dynamic Study of Vertical Loaded Single Pile in Multilayered Saturated Soils. Computational Structural Engineering, Springer, Berlin, Germany pp. 761-769.

8. Sakyi KS (2019) Analysis of layered saturated soil using finite element method. The Open Mechanical Engineering Journal 13(5):57-68. 
9. Sakyi KS (2019) In this research we contemplated on a hybrid statistical technique for the IBVP. This technique encompasses three (3) phases.

10. Sakyi KS (2019) Advanced finite element method in the Laplace transform for both transmission and wave equations used in the field of engineering. The Open Civil Engineering Journal 13(3): 10-21.

11. Sakyi KS (2019) A contrast between indirect boundary element and finite element methods. The Open Mechanical Engineering Journal 13(8):89-99.

12. Sakyi KS (2019) Finite element analysis joined by the Laplace transform to solve the vibration delinquency in toroidal area loops. The Open Civil Engineering Journal 13(4): 22-32.

13. Sakyi KS (2019) 3-D consolidation analysis of layered saturated soil using finite element method. The Open Mechanical Engineering Journal 13(3): 22-45.

14. Sakyi KS (2012) Biot's Theory of Consolidation.

15. Sakyi KS (2019) Finite Element Method of Saturated Soil Structure using the Galerkin Approach. The Open Mechanical Engineering Journal13(11):121-132.

16. Sakyi KS (2019) Finite Element Model of Saturated Soil. The Open Mechanical Engineering Journal 13(6): 69-78.

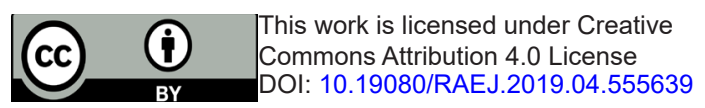

17. Sakyi KS (2019) Modelling of saturated soil dynamic and two-dimensional consolidation problems using three-dimensional scaled boundary finite element method.

18. Sakyi KS (2019) The Coupling of the Biot Model. The Open Civil Engineering Journal 13(9): 21-45.

19. Sakyi KS, Jian-Fei Lu (2019) Application of the Laplace transform to non-rectilinear momentary problems. Innovative system Design Engineering 10(1): 2019.

20. Sakyi KS, Jian-Fei Lu (2019) Finite Element Modeling of Episodic Edifices. Computer engine intelligent system 10(1): 2019.

21.22. Sakyi KS, Benjamin K, Godson K (2018) seismic response analysis of underground structures.

22. Sakyi KS (2019) Application of Finite Element Method for the analysis of periodic saturated soil-structure system. Journal of Solid Mechanics 13: $22-32$.

23. Sakyi KS (2019) How to convert from standard form to a vertex form of a quadratic equation.

24. Sakyi KS (2019) Key concepts of Quadratic Functions and Inequalities.

25. Samuel K, Korankye B, Kweitsu G (2019) Seismic response analysis of underground structures. J Enviro Earth Sci 8(5): 48-63.

\begin{tabular}{l} 
Your next submission with Juniper Publishers \\
will reach you the below assets \\
- Quality Editorial service \\
- Swift Peer Review \\
- Reprints availability \\
- E-prints Service \\
- Manuscript Podcast for convenient understanding \\
- Global attainment for your research \\
- Manuscript accessibility in different formats \\
( Pdf, E-pub, Full Text, Audio) \\
- Unceasing customer service \\
Track the below URL for one-step submission \\
https://juniperpublishers.com/online-submission.php \\
\hline
\end{tabular}

